Please quote as: Ernst,S.; Janson, A.; Söllner, M. \& Leimeister, J. M. (2016): It's about Understanding Each Other's Culture - Improving the Outcomes of Mobile Learning by Avoiding Culture Conflicts. In: International Conference on Information Systems (ICIS), Dublin, Ireland. 


\title{
It's about Understanding Each Other's Culture - Improving the Outcomes of Mobile Learning by Avoiding Culture Conflicts
}

\author{
Completed Research Paper
}

Sissy-Josefina Ernst

\author{
Andreas Janson
}

\author{
University of Kassel \\ Information Systems \\ Pfannkuchstr. 1, 34121 Kassel, Germany \\ [sissy.ernst, andreas.janson]@uni-kassel.de \\ (erm
}

Matthias Söllner

University of Kassel/University of St. Gallen

Information Systems/Institute of Information Management

Pfannkuchstr.1, 34121 Kassel, Germany/Unterer Graben 21, 9000 St.Gallen, Switzerland

[soellner, leimeister]@uni-kassel.de/[matthias.soellner, janmarco.leimeister]@unisg.ch

\begin{abstract}
Mobile learning enables learners to integrate learning activities into daily routines. Information systems research emphasizes that technology-mediated learning (TML) has to be adapted to cultural differences. Integrating a mobile learning application into a new context can cause conflicts as values embedded in the mobile learning application can conflict with values of the context in which it is introduced. With this paper, we propose a theory-driven design approach to avoid culture conflicts in mobile learning. Based on the implementation of a mobile learning application in Chinese vocational schools, we derive requirements from IT-culture conflict theory as well as practice, which are addressed with design elements and implemented in the application. Our results show that cultural adaptation leads to improved cognitive learning outcomes. As a practical contribution, we provide guidance on how to overcome culture conflicts; as a theoretical contribution, we contribute to the exploration of culture in the usage of TML.
\end{abstract}

Keywords: mobile learning application, design science research, IT-culture conflict, learning outcomes 


\section{Introduction}

Mobile learning enables learners to choose the place and time of their learning activities and to interact with lecturers, learning material, and peers (Koole 2009). It is described as a promising way to bring learning into the real world by allowing for a contextual acquisition of skills and direct feedback (Walker 2006; Gómez et al. 2014) and is therefore especially important when integrating learning into daily work practices.

The demand for mobile learning increases worldwide, with China, the United States, and India constituting the largest markets for mobile learning products (Adkins 2015). Increasing globalization compels mobile learning providers to face the challenge of distributing their mobile learning products to growing markets in foreign countries. Individualization and specializing in target groups, such as the adaptation of a mobile learning application to the needs and perceptions of a company, are key factors in a competitive market for learning applications (MMB Institute 2015). However, most providers struggle to consider these factors when it comes down to transferring their mobile learning applications to foreign cultural contexts. As Swierczek and Bechter (2010, p. 291) state, "for learning to be effective, it must be adapted to the cultural context in which it takes place". Therefore, a universal approach may not fit the needs of all learners (Swierczek and Bechter 2010; Downey et al. 2005; Holtbrügge and Mohr 2010). Oftentimes, providers of mobile learning applications fail to export their mobile learning products due to a missing or mismatching orientation to the target groups' cultural values (Fraunhofer MOEZ 2012). As it is inefficient for mobile learning providers to individually develop mobile learning applications for each client's culture, techniques are needed to adapt existing applications to respective cultures. Consequently, the question arises of how providers of mobile learning applications can adapt their existing solutions in a way to not infringe on norms and values of the target culture, which makes it necessary to obtain an understanding for cultural values of the target group.

In this regard, information systems (IS) research refers to the theory of information technology (IT)culture conflicts, which suggests that the role of culture within IT use goes mostly unnoticed unless a conflict occurs (Leidner and Kayworth 2006). By drawing on IT-culture conflict theory, we are able to examine mobile learning as an overall concept, analyzing the learning scenario, learning concept, and IT artifact design from different cultural layers. The goal of our paper is to present a theory-driven design approach in order to provide a set of design elements to overcome culture conflicts in mobile learning for vocational students in China and is based on the following two research questions (RQ):

RQ1: Which IT-culture conflicts occur in the implementation of a mobile learning application in Chinese vocational schools and which design elements resolve them?

RQ2: Does a culturally adapted mobile learning application positively influence learning outcomes of vocational students in China?

With the adaptation of an existing mobile learning application to the needs of our target group, namely Chinese vocational students by deriving requirements from the theory of IT-culture conflict, we seek to improve affective, cognitive, and skill-based learning outcomes. To achieve our research goal, we follow the design science approach (Peffers et al. 2007), which outlines a process model for doing design science research (see Figure 1). Hence, we contribute to the greater body of knowledge with a nascent theory of design and action as an improvement for known problems (Gregor 2006; Gregor and Hevner 2013). By appreciating the role of culture in mobile learning, we contribute to the exploration of cultural characteristics in the usage of technology-mediated learning (TML) scenarios (Chen et al. 1999) and show that the recognition of cultural values significantly influence learning outcomes. Connected to this is the practical contribution of our research, enabling mobile learning providers to adapt mobile learning applications to foreign culture contexts and showing in which cases an adaption process is useful. 


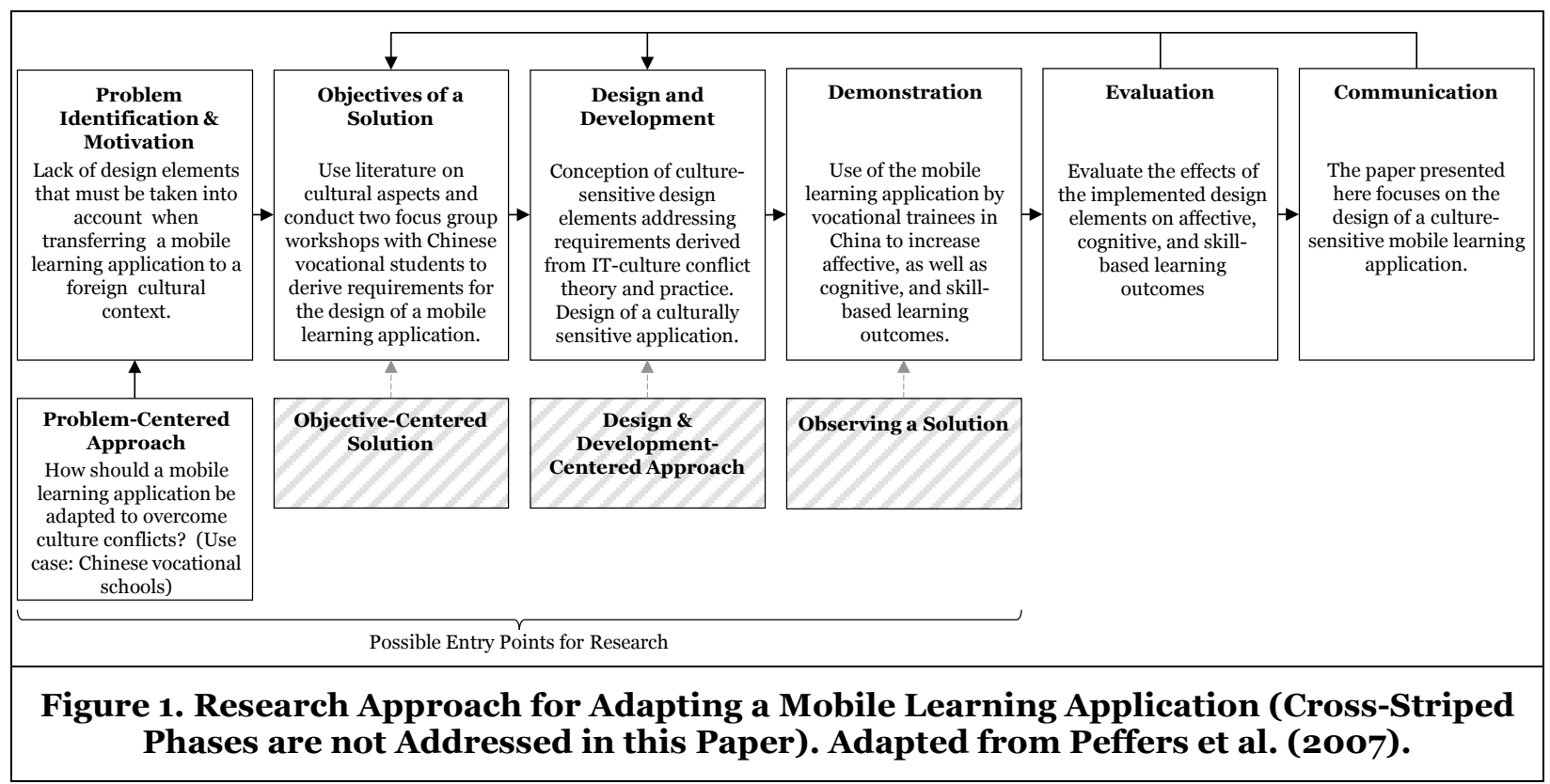

In line with our research approach (shown in Figure 1), we addressed the problem identification and motivation phase of the design science approach in this introduction. The remainder of the paper is organized as follows: The next section focuses on the theoretical background of mobile learning applications, culture in TML, and the theory of IT-culture conflict, which we used as a kernel theory (Gregor and Jones 2007; Walls et al. 1992). We elaborate on this theory as the theoretical basis for our design before addressing the following activities of the design science approach: the objectives of a solution phase by identifying requirements derived from IT-culture conflict theory and by conducting two focus group workshops. The third phase, design and development of the design science cycle, addresses these requirements by culture-sensitive design elements and specifies how these elements were integrated into the mobile learning application with the purpose to positively influence affective, cognitive, and skillbased learning outcomes. Section four of this paper addresses the demonstration and evaluation phases of the design science cycle. The effects of the implemented design elements on learning outcomes are evaluated by conducting a quasi-experiment in Chinese vocational schools. The paper closes with a discussion regarding the results of our experiment in China. Furthermore, we indicate how we contribute to theory and practice and specify limitations of our research before the paper finishes with a brief conclusion. We address the last phase of the design science cycle by publishing this research paper.

\section{Theoretical Background}

\section{Mobile Learning}

Mobile learning allows for spontaneous, ubiquitous, and pervasive learning; it is based on technical feasibility using ubiquitous media (Kukulska-Hulme 2005; Seipold 2014). The learner has access to knowledge and information anywhere and anytime via wireless, portable, handheld, and mobile devices (Pieri and Diamantini 2009). Flexibility and mobility enable real-time interaction with learning materials, lecturers, and peers (Koole 2009), which makes it contextual, situated, and essentially personal (Traxler 2009a). Thus, mobile learning can be considered as a subset of TML, which is defined as "an environment in which the learner's interactions with learning materials (...), peers, and /or instructors are mediated through advanced information technologies" according to Alavi and Leidner (2001, p. 2). When actually applying already acquired factual knowledge, mobile learning especially leads to improved outcomes for learners in terms of training success compared to traditional learning scenarios, as it allows for the provision of immediate and direct feedback (Gómez et al. 2014). Mobile learning is not just about "mobile" or "learning", it is rather part of a new mobile conception of society (Traxler 2009a). In contrast to other types of learning such as paper-based learning, a mobile learning scenario comprises many aspects, such as technology, learner, learning context, learning environment, ways of learning, places and 
time of learning, and so forth (Seipold 2014). In this regard, literature oftentimes calls attention to focusing on the learner's needs and not on usability aspects, style, or the lecturer's wishes (Traxler 2009b). Likewise, research has suggested that users and their cultural differences critically influence the use and learning process in mobile learning and should be taken into consideration when transferring a mobile learning application to foreign contexts (Gupta et al. 2010; Fischer and Kopp 2007; Swierczek and Bechter 2010; Lee et al. 2010).

\section{The Role of Culture in Technology-Mediated Learning}

Culture can be seen from a variety of perspectives. One popular way to explain culture considers norms and values that characterize a culture and distinguish it from another (Leidner and Kayworth 2006; Srite and Karahanna 2006; Gallivan and Srite 2005; Hofstede 1980). Furthermore, there are approaches based on basic assumptions and those using cultural artifacts to describe differences from a cultural point of view (Schein 1984). Since values are more comprehensive than, for example, invisible basic assumptions or indecipherable artifacts (Schein 1984), we follow the value-based approach, which has become prevalent in IS research (Kummer et al. 2012). Culture is not only connected to different definitions of what represents culture but also to different layers of applicability. In this context, Karahanna et al. (2005) proposed the model of interrelated levels of applicability. An individual's culture as the core of the model is the product of all surrounding levels (Karahanna et al. 2005). Following the approach of Karahanna et al. (2005), it needs more than a reflection on values on a national layer to "grasp" someone's culture. This view becomes increasingly relevant when it comes down to a cultural reflection on economies such as China where the cultural development is subjected to constant change (Martinsons and Ma 2009). By grounding our research in IT-culture conflict theory, we examine our target group's culture not only from a national perspective, but also from an organizational and subunit point of view; thus, our study also orientates towards the approach of Karahanna et al. (2005).

Despite extensive research in the field of culture in IS (Kummer and Schmiedel 2016), only few studies used a cultural perspective to investigate the adaptation of TML. Whether it was research regarding culture in IS or TML, most studies refer to the value dimension of anthropologist Hofstede (1986) to explain and differentiate culture (Anakwe et al. 1999; Mushtaha and Troyer 2007; Swierczek and Bechter 2010; Blanchard and Frasson 2005; Marcus and Gould 2000). However, most studies in the field of TML investigate culture on a national level, whereas the organizational perspective on TML receives little attention. While they generally seek to explain culture and aim for the tangibility of a person's culture, studies in the field of culture in TML present a heterogeneous research scope. Research in the field of learning styles is apparent in Renner et al. (2015), Fischer and Kopp (2007), and Holtbrügge and Mohr (2010). Renner et al. (2015) analyzed the impacts of culture and learning styles on learning success. By conducting an empirical study, the authors showed that national culture has an impact on blended learning success. They measured learning success via a questionnaire that describes daily situations of a learner and asks for preferences of reaction. Fischer and Kopp (2007) instead investigated the ability of Chinese learners to adapt their learning style when facing a new teaching approach, thereby demonstrating that Chinese learners have problems to regulate and control the learning process. Apart from the learning style, a second thematic group focuses on the system design of TML. Moreover, the system design has been examined from different perspectives. In IS research, the work of Reinecke and Bernstein (2013) presents an approach to adapt a website to a foreign culture. However, in the field of culture in TML, most research considering the system design is based on cross-country comparisons. Two streams are apparent: On the one hand, studies compare learning systems between countries (Kamentz and Womser-Hacker 2003) and usability criteria (Downey et al. 2005) with the aim to build a system that reflects the cultural orientation of its users. On the other hand, differences regarding the content and user interface of an e-learning system are determined with the aim to find dimensions for internationalization (Mushtaha and Troyer 2007).

In summary, research examining culture in the field of TML is wide-ranging, focuses on different topics, and uses various approaches. Even though no research has shown improved learning outcomes due to the integration of cultural aspects, all authors show evidence for a consideration of culture when considering TML. 


\section{Theory of IT-Culture Conflict}

As previously discussed, culture should be examined from various perspectives. By grounding our research in the theory of IT-culture conflict (Leidner and Kayworth 2006), this paper concentrates on culture not only from a national perspective, but also from the organizational and subunit (or group) level. With IT-culture conflict theory, we are able to consider culture conflicts with IT in a comprehensive way. The theory of IT-culture conflict attributes cultural values to IT. The theory is based on the assumption that cultural aspects only become visible if a conflict occurs, or to put it differently, individuals are not aware of their culture until they are confronted with a counterculture. This is an understanding that is fully in line with the approach by Swierczek and Bechter (2010), who argue that learning eliminates neither cultural differences nor is it itself free of cultural values. Thus, values of the learning artifact can come into conflict with values of the target group (Koch et al. 2013; Leidner and Kayworth 2006). By systematically uncovering potential culture conflicts, misuse or unforeseen use can be counteracted (Koch et al. 2013). The conflicts can be differentiated into three types: vision, system, and contribution conflict. They emerge from IT values, group member values, and values embedded in a specific IT (see Figure 2).

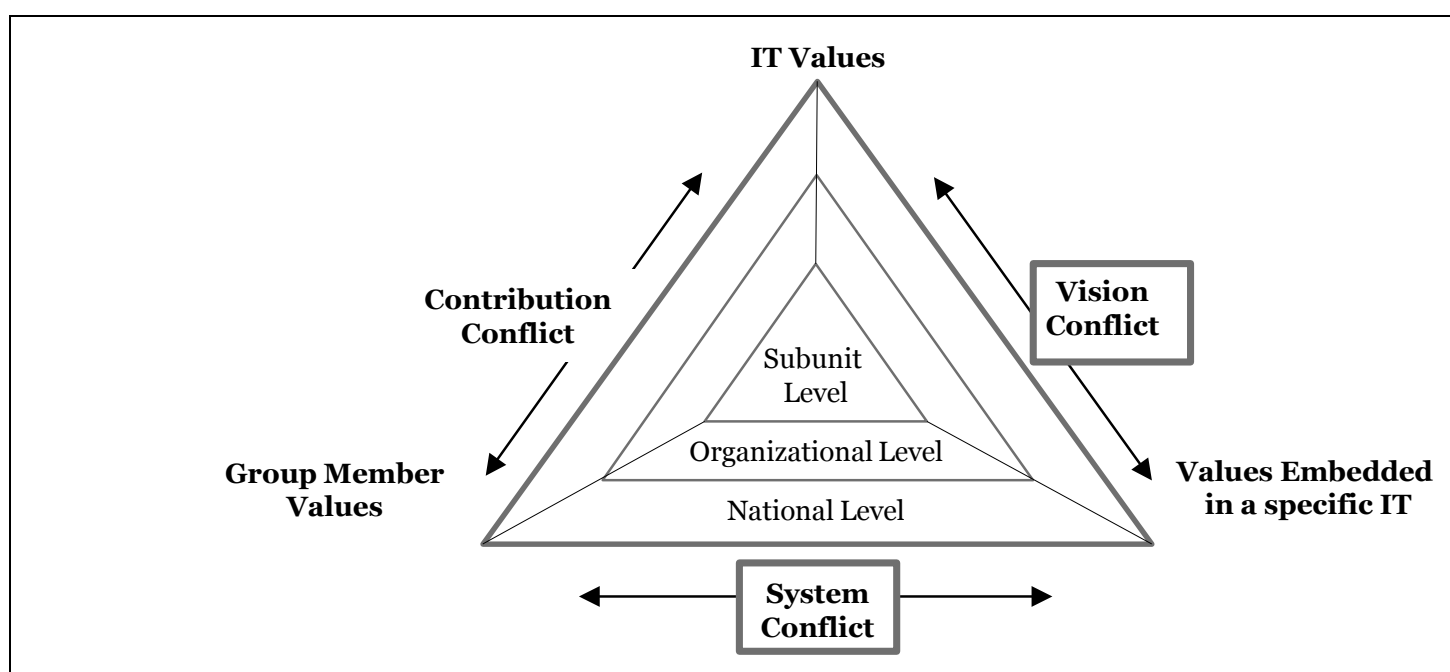

Figure 2. Theory of IT-Culture Conflict Adapted from Leidner and Kayworth (2006)

First, the system conflict describes the conflict that emerges from values embedded in a specific IT artifact, which, in turn, contradict the values held by the group members using the IT artifact. An example would be the transformation of an enterprise resource planning system intended to increase autonomy among the operational levels of a company located in a low power distance country to an affiliated company settled in a high power distance country. As Leidner and Kayworth (2006) point out, the previously described conflict is the most prevalent in research and practice. Second, the contribution conflict explains the contradiction between group member values and the values the group associates with IT in general. To give an example, the contribution conflict can occur when a relationship-oriented group uses IT, even though the group views IT as a tool to promote isolation among people. Third, the vision conflict is a conflict that emerges from a group's IT values associated with IT in general and the values embedded within a specific IT artifact. An example would be to provide software designed to increase efficiency, that is, process management software designed for a group experiencing IT as a timeconsuming burden (cf. Leidner and Kayworth 2006).

In the course of this research paper, we concentrate on vision and system conflicts, since we integrate design elements into our mobile learning application to ensure that no conflicts arise when deploying mobile learning in Chinese vocational schools, thus changing the values embedded in a specific IT artifact. Furthermore, we assume that a mobile learning launch has no short-term effects on group member values and the values the group associates with IT in general, which is fully in line with the suggestion of Leidner and Kayworth (2006) that the contribution conflict will have implications for IT management rather than for IT development and outcome. 


\section{Theory-Driven Design to Overcome Culture Conflicts}

To derive our design for a mobile learning application, we draw on the theory of IT-culture conflict (Leidner and Kayworth 2006) as a kernel theory (Gregor and Jones 2007; Walls et al. 1992). In consequence, the theory-driven design (Briggs 2006; Gehlert et al. 2009) should consider potential culture conflicts that may hinder the use of a specific IT artifact and accordingly address these conflicts in the adaptation process. In particular, we focus on culture conflicts that may occur when providing mobile learning applications in Chinese vocational schools without any adaptation to their cultural preferences. As Leidner and Kayworth (2006) state, groups are more likely to use a technology when their own values fit the values embedded within the technology. As a consequence, users are either reluctant to use or will use a technology in unexpected ways (Koch et al. 2013; Chau et al. 2002). Furthermore, current research states that cultural values influence users' satisfaction with IT (Cyr 2008). In our case of mobile learning applications, changes in user behavior or the kind of use can negatively affect learning outcomes. Hence, culture needs to be considered when adapting mobile learning applications for different culture contexts (Chen et al. 1999; Manikutty et al. 2007). According to Kraiger et al. (1993), the outcomes can be affective, cognitive, or skill-based. This brings us to the assumption that cultural values influence affective learning outcomes regarding users' satisfaction with their own learning process. Hence, we hypothesize:

H1: Participants who use the culturally adapted mobile learning application will achieve higher affective learning outcomes regarding their satisfaction with the learning process compared to participants who use the not adapted mobile learning application.

Concerning the acquisition of cognitive learning outcomes (Kraiger et al. 1993), we expect that the cultural adaptation of our mobile learning application will lead to a higher acquisition of declarative and procedural knowledge (Berry and Dienes 1994) in comparison to a non-adapted mobile learning application. Since the mobile learning application addresses both knowledge types, we hypothesize:

H2: Participants who use the culturally adapted mobile learning application will achieve higher cognitive learning outcomes regarding the acquisition of declarative knowledge compared to participants who use the not adapted mobile learning application.

H3: Participants who use the culturally adapted mobile learning application will achieve higher cognitive learning outcomes regarding the acquisition of procedural knowledge compared to participants who use the not adapted mobile learning application.

Since our initial mobile learning application integrates problem solving scenarios, we expect that the culturally adapted application will lead to improved skill-based outcomes such as the ability to solve a problem. Hence, we hypothesize:

H4: Participants who use the culturally adapted mobile learning application will achieve higher skillbased learning outcomes regarding the acquisition of skill-based knowledge compared to participants who use the not adapted mobile learning application.

\section{Research Setting}

The background of the case presented hereinafter is the vocational training of motor mechanics in Chinese vocational schools. By integrating a mobile learning application into the vocational school context, we seek to increase the students' ability to identify automotive parts and to analyze causes for problems on the car.

The in the following described functionalities refer to a mobile learning application that was developed in Germany and will be transferred to the Chinese vocational school context. This mobile learning application enables students to learn in a context-sensitive way by operating with QR codes that are attached to a demonstration car in the school environment. The mobile learning application offers two different types of learning tasks, each referring to different kinds of knowledge acquisition: The first type of exercise imparts basic knowledge about the automotive parts of the car and thus allows the students to acquire declarative knowledge (Dienes and Berry 1994). Therefore, the mobile learning application displays different components of the car, followed by a request to find the respective component and scan the QR code attached to it. After the student has scanned the intended component, information about the automotive part is introduced followed by a multiple-choice question. Direct feedback is provided after 
answering the multiple-choice question, followed by the next component. An assessment of the student's performance will be given after the completion of all tasks at the end of the first exercise. The second type of exercise facilitates the acquisition of procedural (Dienes and Berry 1994) and skill-based knowledge. The mobile learning application displays different damage descriptions and requires the students to reflect on possible problem causes. The students are asked to work on the car in order to identify the components that they believe have to be examined to solve the problem. By scanning the QR codes of the identified components, little boxes, each presenting a cause of error, are filled with pictures of the error causes and additional information on the fault analysis and the replacement of the defective automotive part is displayed. Besides the design elements that refer to the mobile learning application's functionality, such as the navigation or the boxes that are filled with identified error causes, the design of the initial mobile learning application is kept very simple. The background color of the mobile learning application is white and the displayed buttons are blue. Furthermore, the application has an easy-to-operate 4-button navigation and a progress report. Figure 3 shows our initial mobile learning application.
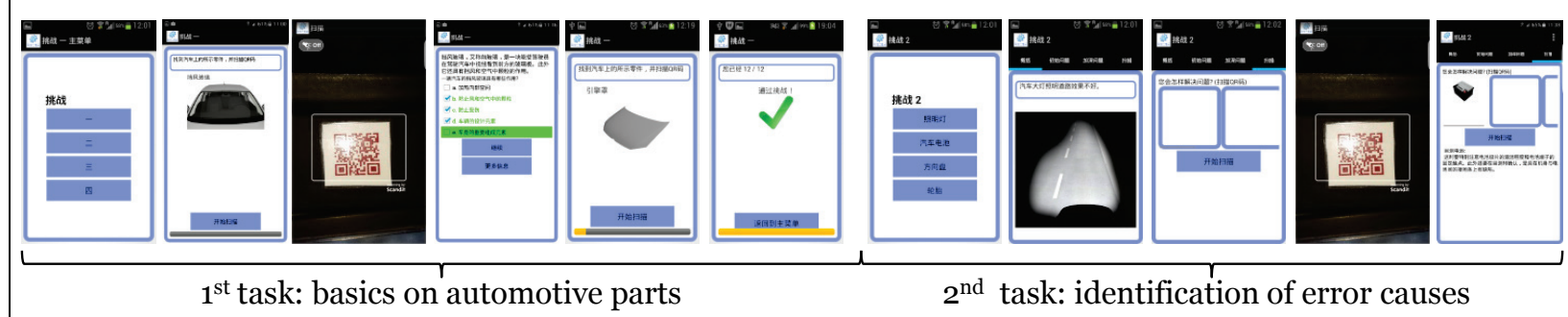

$2^{\text {nd }}$ task: identification of error causes

Figure 3. Initial Mobile Learning Application without Culture-Sensitive Elements

We developed the described mobile learning application that is used as a standard and being transferred to the Chinese vocational school context within an on-going research project by experts in the fields of teaching and training in Germany (Ernst et al. 2015), thus ensuring that the application constitutes a high standard of quality in mobile learning. As already pointed out, we seek to introduce the illustrated mobile learning application in Chinese vocational schools with the aim to increase the students' ability to identify automotive parts and to analyze causes for problems on the car. Since the values embedded in our initial mobile learning application can come into conflict with the values of Chinese vocational students, we consider cultural specifics and adapt the mobile learning application with the intention to overcome culture conflicts. In particular, we seek to change the values embedded in the mobile learning application by integrating theory-driven and practical-driven design elements. Referring to IT-culture conflict theory, an adaptation of the values embedded in the IT-artifact might resolve potential system and vision conflicts.

Our approach to adapt the initial mobile learning application for avoiding culture conflicts includes three steps. As a first step, we derive general requirements concerning mobile learning for China from the theory of IT-culture conflict. We consider mobile learning as an overall concept and examine potential culture conflicts from a theoretical perspective. The theoretical derivation of the requirements considers culture conflicts on a national level. In a second step, we address conflicts regarding the organizational and subunit level by conducting focus group workshops with our target group. Thus, we ensure a more precise cultural fit and take into account that China's society does not constitute a monolithic culture (Li 1996; Cheung and Chow 1999). In the final step, we address all identified culture conflicts with theorydriven design elements.

\section{Requirements from IT-Culture Conflict Theory}

First, we derive requirements from theory to examine IT-culture conflicts on a national level for our case of mobile learning applications in China. In this section, we address the first part of the objectives of the solution phase of the design science approach by Peffers et al. (2007). To summarize, we identify four requirements from theory to ensure that no conflict arises when deploying mobile learning in Chinese vocational schools. 


\begin{tabular}{|l|l|}
\hline $\begin{array}{l}\text { Culture } \\
\text { Conflict }\end{array}$ & Requirements Derived from Theory (R) \\
\hline $\begin{array}{l}\text { System } \\
\text { Conflict }\end{array}$ & $\begin{array}{l}\text { R1) The mobile learning application should offer a lecturer-centered learning approach. } \\
\text { R2) The mobile learning application should ensure the learners' anonymity to the extent } \\
\text { necessary to prevent a loss of face, for example when making a mistake. } \\
\text { R3) The mobile learning application should consider user interface elements that are } \\
\text { preferred by Chinese learners. }\end{array}$ \\
\hline $\begin{array}{l}\text { Vision } \\
\text { Conflict }\end{array}$ & $\begin{array}{l}\text { R4) The mobile learning application should consider elements that reflect the Chinese } \\
\text { learners' expectations and views of mobile applications in general. }\end{array}$ \\
\hline
\end{tabular}

Table 1. Requirements Derived from Theory of IT-Culture Conflict

The first requirement deals with a system conflict within different learning concepts that are embedded in the IT artifact and concepts used in everyday school life. In China, the teacher plays an outstanding role in the learning process. The teacher guides the students through different teaching cases and represents a person the students look up to (Gao 1998; Yu 1959). The teacher is a model of good conduct and learning (Gao 1998). In contrast to the lecturer-centered approach in Chinese schools where the effectiveness of learning is related to the excellence of the teacher (Hofstede 1986), mobile learning provides the possibility to learn in self-regulated ways (Sha et al. 2012). Our mobile learning application enables the vocational students to choose the place and time for their learning activities and allows the students to improve outside the classroom on a self-regulated basis. In consequence, we assume that our mobile learning application, without administering guidance or instructions, might conflict with the Chinese students being used to be guided through different tasks. To prevent a system conflict, the design of the mobile learning application has to consider a lecturer-centered approach by providing additional guidance during the learning process (R1). The second system conflict requirement deals with the issue of a loss of face in the learning process. Redding and Ng (1983) point out that overseas Chinese tend to lose face when feeling ashamed. Chinese students generally feel immense pressure to obtain high academic achievements (Lin and Chen 1995). Examining mobile communication technology in Chinese schools, Rau et al. (2008) call attention to the fact that media demanding self-exposure might increase the pressure to succeed. Thus, we assume the value of a fully transparent training process might conflict with the group's value of feeling ashamed when bad scores are displayed to other students or the teacher. Since a loss of face (Redding and $\mathrm{Ng}$ 1983) would hinder the use and effectiveness of the mobile learning application, the mobile learning application should ensure the learners' anonymity to prevent such a loss of face and thus overcome a potential system conflict (R2). The last system conflict we could identify deals with different preferences regarding the design of the user interface of our mobile learning application. Design preferences are a typical consideration of cultural differences in IS research (Reinecke and Bernstein 2013; Marcus and Gould 2012). The Chinese target group of vocational students is used to different IT designs and might refuse to use a mobile learning application that does not take their preferences and design habits into account. We also recognize this need and therefore require our design to consider such preferences (R3). Cultural differences have a significant impact on the adoption of smartphones (Arpaci et al. 2013). Considering our case, mobile applications in China are mainly used for relaxation and entertainment (CNNIC 2012). Reading, playing games, watching videos, or listening to music are the main purposes for Chinese students to use their smartphones. Hence, a vision conflict can arise when introducing a mobile application that does not consider habitual motives of usage but is instead solely designed for learning purposes. Thus, the last requirement deals with the consideration of the vision conflict in order to enable a fit of the specific IT artifact and the general values the user group assigns to the IT artifact (R4).

\section{Requirements from Focus Group Workshops}

Besides the theoretical derivation of the requirements, we conducted two focus group workshops generating ideas in a moderated discussion with a group of individuals with homogeneous characteristics (Greenbaum 1998) - with our target group, namely Chinese vocational trainees, to derive additional 
requirements from practice. Hence, we address the second part of the objectives of the solution phase of the design science cycle, as shown in Figure 1. By conducting focus group workshops with Chinese vocational students, we seek to gain deeper insights into the culture of our target group on an organizational and subunit level, since "a particular strength of the methodology is the possibility for research participants to develop ideas collectively, bringing forward their own priorities and perspectives (...)”, as Smithson (2000, p. 116) states.

We conducted our workshops in two vocational schools in China. Both schools are located in industryoriented provinces in the east of China. The aim of the workshops was to identify potential culture conflicts on an organizational and subunit level. Therefore, we used the qualitative approach of focus groups because this method is considered effective to gather differing ideas and to generate meaningful information about consumer attitudes (Greenbaum 1998). The first workshop counted 22, the second workshop 19 participants. The majority of the participants were male students and in their first and third year of motor mechanics training having an average age of 18.3 and 19.0 years. Thus, the workshop participants had a common set of information about age, origin, and profession, addressing the requirements of focus groups consisting of participants with homogeneous characteristics (Greenbaum 1998; Barbour 2008). We structured the focus group workshop following the collaboration process design approach by Kolfschoten and Vreede (2009), offering space for discussion and the exchange of information. An early prototype of the original mobile learning application translated into Chinese was provided. With the prototype at hand, the students had to complete different tasks. For example, they were asked to study basic learning material, answer multiple-choice questions, and find solutions to complex problems. Afterwards, we guided the students through different collaborative process steps.

The first step of the collaborative process consisted of a brainstorming unit. It served to collect the students' feedback about negatively perceived aspects concerning the application and their experience using the early prototype. After they had written down their change requests on cards, the students were asked to discuss their wishes for improvement in groups of five. The discussion was moderated to guarantee that each participant had a clear conception of the written change requests. Similar change requests were compiled to clusters. These clusters were rated according to their perceived significance by attaching adhesive points to the respective change requests. In the next phase, each group presented the aspects with the highest scores to the class. The hereinafter described requirements from practice (P) resulted from the most prevalent aspects that were mentioned by at least two groups.

Most participants were not satisfied with the user interface of the mobile learning application we provided in the initial application. The students asked for multimedia content and pictures to improve the design, described the color to be boring and monotone, and asked for a color change. Thus, the first requirement derived from practice deals with the user interface, which should include bright colors and animated pictures (P1). Furthermore, many students mentioned the missing support of the mobile learning application to perform the tasks. They found the handling of the application difficult and asked for further advice and hints about how to use the application and perform the tasks. We therefore noted that the mobile learning application should integrate instructions that provide guidance for tasks (P2). The participants also asked for feedback after each task. Consequently, the mobile learning application should integrate direct feedback after the task performance (P3). These aspects were mentioned most frequently. Additionally, some groups asked for animated games and the chance to compare their results with others. We asked the students whether the teacher should be informed about the results the students achieve. All students denied the forwarding of results to the teacher. Based on this information, we derived three additional requirements. First, the mobile learning application should integrate gamification elements (P4). Second, the mobile learning application should allow for a comparison of results (P5). Third, the mobile learning application should not provide any scores to the teacher (P6).

All requirements address particular aspects of the mobile learning application and provide detailed insights into student expectations toward such an application. We conducted a survey with the workshop participants based on the general workshop assessment (Briggs et al. 2014) to measure their satisfaction with the collaboration process. The survey tested the participants' perceived satisfaction with the workshop process and outcome (Briggs et al. 2014). All items were measured on a 7-point Likert scale. In brief, the results of the one-sample t-test with 4 as the reference value show that the average process satisfaction was rated $6.3(\mathrm{p}<0.001)$ in the first, and 6.0 $(\mathrm{p}<0.001)$ in the second workshop. The 
satisfaction with the workshop outcome was rated $5.7(\mathrm{p}<0.001)$ and $5.8(\mathrm{p}<0.001)$. The results reflect a high degree of satisfaction with the workshops and the results.

\section{Design Elements to Overcome Culture Conflicts and Examples of Implementation}

Addressing the design and development phase of the design science approach, the following section deduces design elements concerning the identified requirements derived from IT-culture conflict theory. Furthermore, we describe how the design elements were integrated into the mobile learning application (see Table 2).

To address the first requirement derived from the theory of IT-culture conflict (R1), we decided to integrate a virtual character. Virtual characters can be used in TML environments to facilitate learning and to give instructions on the learning process (Park 2015). The virtual character appears whenever a teacher in a real learning scenario would talk, help, or provide guidance to the learners. Besides giving instructions on how to perform a task, the virtual character gives direct feedback on the students' learning results, thus addressing the additional requirements of feedback integration derived from the focus group workshops ( $\mathrm{P}_{2}$ and $\left.\mathrm{P}_{3}\right)$. The life-like virtual character has the appearance of a motor mechanic to help the students identify with him. Furthermore, the appearance follows the approach of the Chinese considering light skin to be beautiful (Hernig 2012). The screenshots (see Table 2) show our virtual character named "MoKe". The first screenshot shows him giving instructions on how to perform a task; the second screenshot shows him explaining the initial cause of error at the end of a task. Furthermore, MoKe offers praise for a job well done (this element was combined with gamification).

To address requirements $\mathrm{R}_{3}$ and $\mathrm{P} 1$, we paid attention to the user group and their cultural background during the user interface design process. The recipients of the learning application are vocational students in the field of motor mechanics in China. Therefore, we implemented design elements based on existing user interface research addressing the Chinese culture (Reinecke and Bernstein 2011), drawing on a valuebased approach (Hofstede 1980) and considering the requirements derived from practice. According to the preferences of Chinese people, we adapted the user interface taking culture-specific requirements into account. According to the meta-analysis of Reinecke and Bernstein (2011) based on the insights of Hofstede's dimensions (Hofstede 1980), Chinese users prefer a contrasting interface with bright colors and image icons on the menu. The user interface of the adapted mobile learning application has been changed accordingly. The screenshots on the top (Table 2) demonstrate the basis (initial learning application); the application below integrates China-specific user interface design elements. First, we changed the color of the application from white to yellow (all screens). Second, we changed the shape and color of the buttons from angular shaped blue buttons to bright yellow buttons with rounded corners (all screens). Third, we integrated little images to support the navigation (second screen) and the scan process (third screen). Other elements Chinese users prefer, such as strict error messages (fourth screen), had already been integrated into the basic application and resulted in no need for change.

Since our basis already complies with requirements R2 and P6 to ensure learner anonymity, we decided to consider these requirements when selecting a gamification element. On average, 62 percent of all Chinese go online via a smartphone for relaxation and entertainment (CNNIC 2012). Since Chinese students will most likely not use a mobile learning application without extrinsic incentives, we applied the concept of gamification, that is, using game elements in a non-game context (Hanus and Fox 2015; Thiebes et al. 2014), which offers great potential for motivating IS users (Thiebes et al. 2014). Besides motivating the students to use the mobile learning application, we integrated the gamification elements to additionally provide feedback $\left(\mathrm{P}_{3}\right)$ and allow the students to compare their results with others on a voluntary basis $\left(\mathrm{P}_{5}\right)$. As a result, we acquired a better fit to the usage habits of Chinese students and hence overcome the vision conflict. The first screenshots in Table 2 show our approach to transform "MoKe" into the gamification element "loss aversion" (Thiebes et al. 2014). Every time students fail to answer a multiplechoice question, "MoKe" loses vital energy. After he has lost all of his energy, the students are asked to repeat the task. The level stops and restarts. To allow for improvement, feedback is given directly after each question. Corrections are given equally in the culturally adapted and the initial application. The screenshots in the second line show the integrated gamification element "achievement" (Thiebes et al. 2014). While the initial mobile learning application gives an unemotional feedback, the students using the culturally adapted mobile learning application have the opportunity to earn a trophy for their achievements. The students win either a golden or a silver trophy depending on the number of correct 
answers given and not in dependence on the results of other classmates. Hence, we assume to motivate the students to use the mobile learning application on a voluntary basis. Furthermore, the students can challenge each other without public ranking.

Table 2 presents the composition of the requirements and the corresponding culture-sensitive design elements and shows examples of implementation.

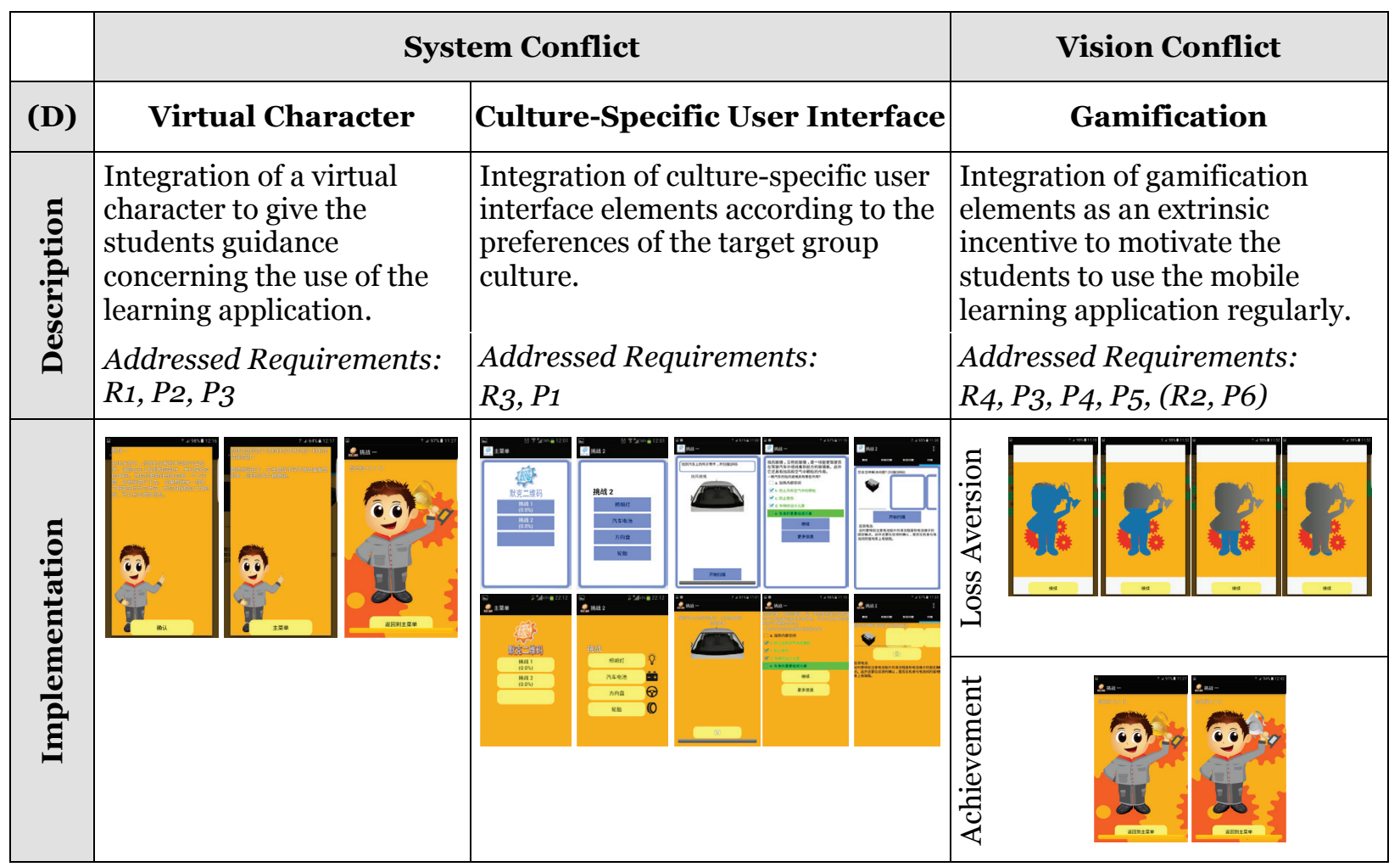

Table 2. Design Elements for Mobile Learning in China

\section{Evaluation}

With the following evaluation of our implemented design elements, we address the demonstration and evaluation phases of the design science cycle. In particular, the use of the mobile learning application by Chinese vocational students refers to the demonstration phase, whereas the results of our conducted experiment make reference to the evaluation phase of the design science cycle.

\section{Methodological Aspects}

For the evaluation, we conducted a quasi-experiment in China. The data collection was done in November 2015. To evaluate the impact of the implemented design elements, we used both mobile learning applications. On the one hand, we used the initial mobile learning application as the reference application; on the other hand, we used the mobile learning application with the implemented design elements to overcome culture conflicts. Both applications were identical in terms of learning content and the basic learning scenario to ensure the isolated effect of our implemented measures. The evaluation took place within vocational teaching scenarios in Chinese vocational schools. Our test subjects were vocational students of the automotive business. The overall learning goal of our conducted quasi-experiment was twofold. Both groups were asked to work on the fundamentals ( $1^{\text {st }}$ task) first and to train the error analysis and handling regarding the front lighting system of a car ( $2^{\text {nd }}$ task) afterwards. In brief summary, we trained declarative knowledge by teaching fundamentals and procedural and skill-based knowledge by asking the participants to develop a strategy to detect a cause of damage and solve the issue. Figure 4 provides an overview of our experimental procedure. 


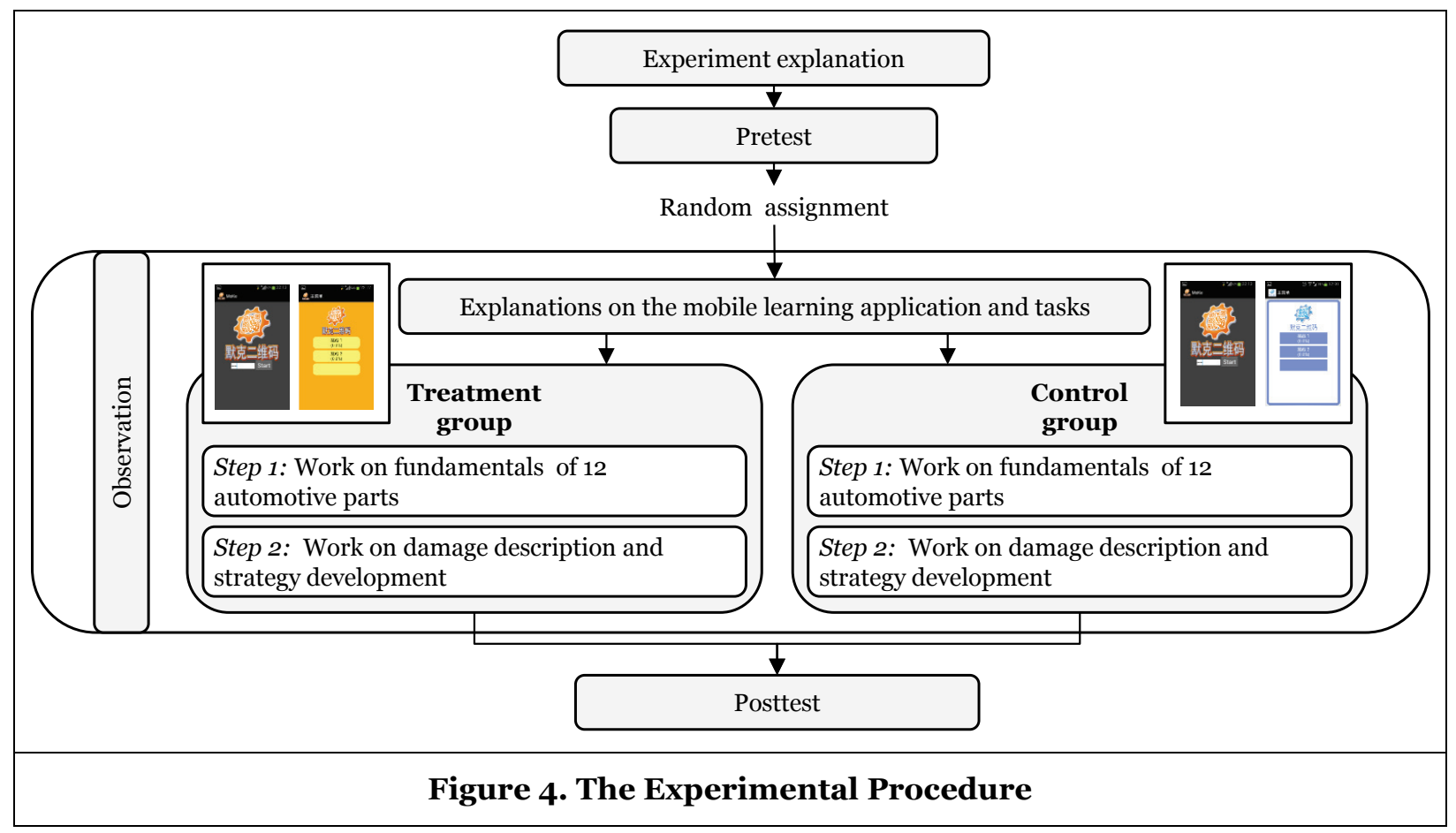

We divided the students into two groups; one group used the adapted culture-sensitive application (treatment group), and the second group used the unmodified initial mobile learning application (control group). Since we conducted our experiment in a real field, a full randomization of the test subjects was not possible. During the experiment, small groups of up to 12 students worked simultaneously on the car. Each trainee was allowed to participate in the quasi-experiment only once. All students were allowed to use their own mobile devices during the quasi-experiment. We worked with only one installation file for both versions of the mobile learning application. To ensure that the students did not share any version of the mobile learning application with others, the mobile learning application requested a start code, which we kept secret. Depending on the start code entered into the system, either the initial mobile learning application or the adapted application loaded. The whole process was overseen by two study proctors, both Ph.D. candidates in an IS department.

We started the experimental procedure with a short explanation of our experiment. We therefore worked together with two translators who had technical language skills regarding IT and automotive trainings. Afterwards, all participants had to take a pretest that contained a subset of questions from the content the mobile learning application provides. After taking the pretest, the students were asked to install the installation file on their mobile devices. After we made sure that each participant had a running application, we explained the mobile learning application and the tasks they had to work on. Once we entered the start code, the students were asked to work on the fundamentals of 12 automotive parts first and to switch over to the damage description after they had finished the first task. In total, the mobile learning unit corresponds to one school lesson. Afterwards, all participants were asked to take a posttest. Overall, 201 vocational students participated in the quasi-experiment.

To measure the learning outcomes, we drew on the approach by Gupta and Bostrom (2013) and measured the affective outcomes as well as cognitive and skill-based knowledge acquisition. We measured the students' affective learning outcomes regarding their satisfaction with the learning process using the process scale from Green and Taber (1980). To measure their cognitive knowledge acquisition, the students were asked to answer 16 single-choice questions regarding the acquisition of procedural und declarative knowledge. Furthermore, we developed a concept map visualizing a complex fault tree with an expert in didactics, who is also a project member and currently Ph.D. candidate. As Nesbit and Adesope (2006, p. 415) state, "A concept map can be regarded as a type of graphic organizer that is distinguished by the use of labeled nodes denoting concepts and links denoting relationships among concepts." Concept maps are often used as media for constructive learning activities and are associated with increased knowledge retention (Nesbit and Adesope 2006). In our case, we designed a concept map showing ways to 
identify the problem of a poor roadway illumination and indicating conditions for fault removal. In the experiment, we then asked the students to detect and correct the hidden flaws. To evaluate the impact of the design elements on the dependent variables, we used a t-test to evaluate whether there is a significant improvement in learning success. To obtain rich insights regarding the use process of our artifact under investigation, we additionally observed how the participants in our experiment interacted with the provided prototypes.

\section{Results}

The participants of our experiment were students from the first to the fourth year of training and predominantly male. The control group counted 94, the treatment group an average of 107 participants. The following table gives an overview of the descriptive statistic of our quasi-experiment.

\begin{tabular}{|c|c|c|c|c|c|c|}
\hline \multirow[t]{2}{*}{ Description } & \multicolumn{6}{|c|}{ Value } \\
\hline & \multicolumn{2}{|l|}{ Total Sample } & \multicolumn{2}{|l|}{ Control Group } & \multicolumn{2}{|c|}{ Treatment Group } \\
\hline Gender & $\begin{array}{l}\text { Female }(n=5) \\
\text { Male }(n=189) \\
\text { No Answer }(n=7)\end{array}$ & $\begin{array}{l}3 \% \\
94 \% \\
4 \%\end{array}$ & $\begin{array}{l}\text { Female }(\mathrm{n}=4) \\
\text { Male }(\mathrm{n}=86) \\
\text { No Answer }(\mathrm{n}=4)\end{array}$ & $\begin{array}{l}4 \% \\
91.5 \% \\
4 \%\end{array}$ & $\begin{array}{l}\text { Female }(n=1) \\
\text { Male }(n=103) \\
\text { No Answer }(n=3)\end{array}$ & $\begin{array}{l}1 \% \\
96 \% \\
3 \%\end{array}$ \\
\hline Age & $\begin{array}{l}\text { Mean } 17.7 \text { Years } \\
\text { S.D. 1.62 Years } \\
\text { Median } 18 \text { Years } \\
\text { Range } 15-22 \text { Years } \\
\text { No Answer }(n=9)\end{array}$ & & $\begin{array}{l}\text { Mean } 17.78 \text { Years } \\
\text { S.D. } 1.59 \text { Years } \\
\text { Median } 17 \text { Years } \\
\text { Range } 15-22 \text { Years } \\
\text { No Answer }(n=5)\end{array}$ & & $\begin{array}{l}\text { Mean } 17.64 \text { Years } \\
\text { S.D. } 1.66 \text { Years } \\
\text { Median } 18 \text { Years } \\
\text { Range } 15-22 \text { Years } \\
\text { No Answer }(n=4)\end{array}$ & \\
\hline
\end{tabular}

Table 3. Demographics

As outlined in the table, the participants of the treatment group and control group were about the same age. There were no statistically significant differences between the control and the treatment group. In total, we had a wide age range from 15- to 22-year-old participants corresponding to the academic year from the first to the fourth year of training. Nine participants refused to report their age. Altogether, only five female students participated in our experiment. Since our addressees are vocational students of the automotive business, this unequal distribution between male and female participants covers our perception of their school life.

Starting with our experiment, we asked the trainees to do a knowledge test before testing the application. The students' level of knowledge regarding both declarative and procedural knowledge was retrieved by single-choice questions. In total, the pretest contained four questions per knowledge type. The results of the pretest are presented in the table below.

\begin{tabular}{|l|l|l|l|l|l|}
\hline \multirow{2}{*}{ Construct } & \multicolumn{2}{|l|}{ Control Group } & \multicolumn{2}{l|}{ Treatment Group } & \multirow{2}{*}{ t(df) = t-value, p-value } \\
\cline { 2 - 5 } & Mean & $\boldsymbol{N}$ & Mean & $\boldsymbol{N}$ & \\
\hline Declarative Knowledge & 2.260 & 92 & 2.330 & 106 & $\mathrm{t}(196)=-0.504, \mathrm{p}=0.615$ \\
\hline Procedural Knowledge & 2.945 & 91 & 2.990 & 107 & $\mathrm{t}(196)=-0.411, \mathrm{p}=0.682$ \\
\hline
\end{tabular}

Table 4. Pretest - Comparison between Control and Treatment Group's Prior Knowledge

The mean value between control and treatment group regarding both declarative and procedural knowledge does not vary statistically. Thus, it is assured that the participants of both groups have an equal prior knowledge base regarding the content of the mobile learning application.

To test the proposed hypotheses of our study, we measured three types of learning outcomes as our dependent variables: affective, cognitive (acquisition of declarative and procedural knowledge), and skillbased learning outcomes. After using the mobile learning application, the participants were asked to fill out a posttest. We used a one-tailed test to evaluate our prior derived hypotheses H1-H4. The following table summarizes the findings. 


\begin{tabular}{|c|c|c|c|c|c|}
\hline \multirow[t]{2}{*}{ Construct } & \multicolumn{2}{|c|}{ Control Group } & \multicolumn{2}{|c|}{ Treatment Group } & \multirow[t]{2}{*}{$t(d f)=t-v a l u e, p$-value } \\
\hline & Mean & $N$ & Mean & $N$ & \\
\hline \multicolumn{6}{|l|}{ Affective Learning Outcomes } \\
\hline Satisfaction with Learning Process & 5.645 & 91 & 5.845 & 102 & $\mathrm{t}(191)=-1.282, \mathrm{p}=0.101$ \\
\hline \multicolumn{6}{|l|}{ Cognitive Learning Outcomes } \\
\hline Declarative Knowledge & 4.886 & 88 & 4.990 & 101 & $\mathrm{t}(187)=-0.543, \mathrm{p}=0.294$ \\
\hline Procedural Knowledge & 5.101 & 89 & 5.407 & 103 & $\mathrm{t}(190)=-1.654, \mathrm{p}=0.050$ \\
\hline \multicolumn{6}{|l|}{ Skill-Based Learning Outcomes } \\
\hline $\begin{array}{l}\text { Skill-Based Knowledge (Concept } \\
\text { Map - Flaw Ident. \& Correction) }\end{array}$ & 0.957 & 94 & 1.700 & 107 & $t(199)=-4.146, p<0.001$ \\
\hline
\end{tabular}

Table 5. Posttest - Comparison between Control and Treatment Group's Learning Outcome

The results show that the students using the culturally adapted mobile learning application were more satisfied with the learning process, even though not significantly. Hence, we have to reject our prior derived hypothesis H1. Furthermore, the treatment group performed better in answering questions regarding the acquisition of both declarative and procedural knowledge. Concerning procedural knowledge, the treatment group achieved significantly better results. For $\mathrm{H} 2$ and $\mathrm{H} 3$, we argued that our culturally adapted mobile learning application would lead to increased cognitive learning outcomes, regarding either the acquisition of declarative (H2) or procedural knowledge (H3). In this regard, the results confirm solely $\mathrm{H}_{3}$ and reject H2. Major differences between both groups appear in the ability to solve complex tasks. Therefore, the trainees were asked to identify and correct flaws in a concept map. In sum, four flaws were hidden in the concepts maps. The ability of the treatment group to find and correct these flaws is significantly more distinct. We argued that participants using the culturally adapted mobile learning application would achieve better skill-based learning outcomes. Thus, we are able to support $\mathrm{H}_{4}$.

In addition, we conducted a direct observation (Bhattacherjee 2012) to gather insights into how the participants of the experiment used the provided prototypes. The analysis showed that the participants, regardless of the prototype, needed comprehensive explanations at the beginning of the learning process regarding the learning scenario itself. However, the participants in the treatment group, who were provided with virtual character-based explanations, had a better initial orientation while using the mobile learning application. Considering the impact of the implemented gamification elements, specifically the gamification element of "MoKe" loosing vital energy, we noticed that some participants in the treatment condition were terrified about "MoKe" loosing energy. One participant mentioned that he finds it cruel to see "MoKe" dying. Moreover, we noticed that the participants of the treatment group increasingly concentrated on performing the tasks. On the one hand, the participants spent more time on reading the information given and on placing their tick marks to answer the multiple-choice questions. On the other hand, they tried to adopt the solutions given after each question to achieve better outcomes in the case of "MoKe" losing all of his energy. Some students appeared to be unmotivated to continue after "MoKe" had lost all of his energy several times. Regarding the design of the user interface, we could not find any major differences between both groups. Furthermore, we recognized little differences concerning the way the final results of the performed tasks were summarized and reported. The participants of both groups seemed to be proud of their results, disappointed, or resigned, but a few students of the treatment group showed their screen, thus reporting their results to other participants. We could not observe this behavior among students of the control group.

\section{Discussion and Implications}

To the best of our knowledge, we are the first utilizing the theory of IT-culture conflict by Leidner and Kayworth (2006) to adapt a mobile learning application. For the purpose of addressing cultural values on different cultural layers, we derived theoretical requirements from the theory of IT-culture conflict and practice, and addressed these by design elements. We explicitly consider IT artifacts and their according values, as well as IT-culture conflicts that are induced by implementing such an IT artifact in a foreign 
culture. Therefore, we provide a new theoretical lens in the context of cross-cultural studies that in contrast often relate to one fixed technology in different cultures (e.g. Straub 1994; Kamentz 2011). We hypothesized that mobile learning being adapted to the cultural values of the context in which it is introduced would lead to improved affective, cognitive, and skill-based learning outcomes. We evaluated the adapted mobile learning application in a teaching scenario of Chinese vocational schools to investigate the learning outcomes. One key contribution of the study is the practical illustration of how to adapt a mobile learning application for a foreign cultural context through the concept of culture conflicts, analyzing the implementation of an initial mobile learning application from a national, organizational, and subunit culture perspective. Therefore, our study offers a generalizable approach to design TML artifacts that specifically consider IT-culture conflicts, thus helping to ensure the outcomes of the implementation of innovative learning scenarios. More importantly, the study shows that avoiding culture conflicts in the field of mobile learning leads to significantly improved procedural and skill-based knowledge acquisition when compared to a mobile learning application that is not adapted to the values of the target group, but identical in content.

Considering our first RQ, we identified various culture conflicts on the basis of the theory of IT-culture conflict (Leidner and Kayworth 2006) while integrating a mobile learning application in the context of Chinese vocational training. By relying on theoretical insights, we were able to identify four requirements related to the system and vision type of IT-culture conflicts. We agree with Koch et al. (2013) who state that conflicts predominantly occur in the area of system conflicts. We identified value differences in learning concepts, content presentation, and the habitual motives of smartphone usage by examining the Chinese culture from a national perspective based on theoretical reasoning. By conducting focus group workshops with our target group, we were able to additionally derive requirements on an organizational or subunit level and thus gain a better fit regarding our target group's cultural values. The requirements derived from practice appeared to be similar to those derived from theory. However, when taking a closer look, the requirements derived in the focus groups are more specific and provide more guidance for design solutions to circumvent IT-culture conflicts. This is especially prevalent if we consider the integration of gamification elements, while considering making user data anonymous (R2). When relying solely on theoretical reasoning from a viewpoint that considers culture as something that is monolithic, in our case the Chinese one, we possibly would not have designed gamification elements that only enable to compare with other peers on an offline basis. Since the theory-driven requirements conflicted with each other ( $\mathrm{R} 2$ and $\mathrm{R} 4$ ), the practical requirements from the focus group workshops, as well as rich interactions with the target group, provided a more specific design guidance, helping to resolve issues between conflicting requirements. In line with this procedure, we addressed the other IT-culture conflicts by the provision of more guidance in the learning process. In order to do so, we integrated a virtual character. Furthermore, we changed the user interface according to the target group's preferences.

With regard to the second RQ, we evaluated the culturally adapted mobile learning application in a quasiexperiment in Chinese vocation schools. Our results show that the adapted mobile learning application leads to significantly improved cognitive learning outcomes regarding the acquisition of procedural und skill-based knowledge. The concept maps testing the students' acquired skill-based knowledge especially showed highly significant differences between both groups. Concept maps visualizing complex fault trees are a common method to teach vocational students interrelations between problems and are used in the field of motor mechanics training (Pierre-Antoine et al. 2014). We recognized that students of the treatment group were able to associate the second task of the mobile learning training with the concept map more often, while students of the control group failed to create a link. We assume that the additional instructions provided by "MoKe" might have led to an easier intellectual linkage between the mobile learning task to detect error causes, the concept map showing a problem, and possible problem-solving solutions. Although we observed an increased concentration when answering the multiple-choice questions, the implemented design elements had solely positive effects on the acquisition of procedural knowledge. Unlike declarative knowledge, procedural knowledge corresponds to higher-order learning goals, such as applying knowledge or analyzing problem situations (Bloom 1956). We assume the integrated gamification elements might have increased the students' ability to achieve higher skill-based learning outcomes and to acquire procedural knowledge, which complies with the findings of Domínguez et al. (2013) showing that gamified activities in TML help to develop practical competences. Finally, we could not determine any effects regarding an increased satisfaction with the learning process as an affective learning outcome. Taking the results of our observations into account, we assume the 
gamification element "loss aversion" had a negative impact on the students' satisfaction with the learning process, which is in line with the research results of Hanus and Fox (2015) stating that gamification elements can have a negative effect on students' satisfaction in the context of learning. Furthermore, we assume that our implemented design elements only have a slight influence on the satisfaction with the learning process, since the dominant processes of scanning QR codes and detecting possible error causes determine the learning process.

From a theoretical point of view, our results confirm the argument of Swierczek and Bechter (2010) that effective TML must be adapted to the cultural context in which it takes place. However, we showed that cultural contexts, such as the Chinese one, cannot be seen as monolithic, even for the development of successful IT artifacts. When referring to research regarding espoused cultural values (e.g., Srite and Karahanna 2006; Chen and Zahedi 2016), culture is shaped by various reference layers that have to be recognized when considering the effects on learning outcomes (Janson et al. 2016). Theorizing about a national level perspective for the design rationale might have led to other requirements. For example, considering the collectivistic nature of the Chinese, which is theorized by Hofstede's insights, could have led us to a more collaborative mobile learning application where user data is shared among learners. Instead, our holistic approach considered multiple reference levels for the design rationale, therefore leading to non-intuitive design decisions that followed a more individualistic learning approach where learners earn certain gratifications without directly competing with other learners. Furthermore, our results show that learning outcomes that correspond to higher-order learning goals can be improved by the integration of culturally derived design elements into mobile learning. With our paper, we provide several contributions to theory. We contribute to the exploration of cultural characteristics in the usage of TML scenarios. In particular, we provide a deeper understanding of mobile learning and its adaptation to foreign contexts and expand the understanding of the theory of IT-culture conflict, which we used as a kernel theory. In addition, with a systematic evaluation of design elements derived from IT-culture conflict theory, our paper contributes to IS design science research (Gregor and Hevner 2013). According to the contribution types by Gregor and Hevner (2013), we contribute a situated implementation of an IT artifact to design science theory. The contribution is demonstrated by showing significantly improved skill-based and procedural knowledge, which proves the concept. By using IT culture conflict theory to adapt a mobile learning application to a foreign context, we develop a new solution for the acknowledged problem of culture influencing TML. From a practical perspective, our implications for mobile learning providers as well as designers of mobile learning applications are manifold. First, we were able to show highly beneficial effects of the cultural adaptation of our mobile learning application on skill-based learning outcomes and the acquisition of procedural knowledge. However, as we have seen from our results, we were not able to improve the satisfaction with the learning process and declarative knowledge acquisition. Second, we provide an approach on how to adapt an existing mobile learning application to the values of a certain context and thus enable providers to transfer their mobile learning applications to foreign contexts by considering the target groups' values.

\section{Limitations and Future Research}

Regarding construct validity, we examined cognitive, affective, and skill-based learning outcomes as the central factors for the success of mobile learning; we also investigated how to enhance these constructs with mobile learning applications adjusted to the target group's context. Since we were not able to derive any indications concerning a prevented culture conflict, future research should examine this by conducting interviews. Furthermore, external validity might be compromised regarding the generalizability of the findings. Therefore, IT-culture conflict theory should also be considered in other implementation projects to also obtain further insights regarding the generalizability of our approach. In this regard, the target culture of the adaptation process should be chosen differently. For example, the adaptation to organizational values as part of a TML implementation project might lead to new insights. Moreover, we did not examine potential contribution conflicts that might also happen according to the theory of IT-culture conflicts (Leidner and Kayworth 2006). A long-term study could therefore examine whether integrating a mobile learning application has an effect on the values a group associates with mobile learning. Regarding our adaptation project, the results show that it needs further theoretical foundations in between the theoretical derivation of design elements and the selection process of implemented elements. For example, the design element "gamification" allows for a variety of different design options, which in turn can cause manifold effects in different cultural contexts. Moreover, the 
identification process of culture conflicts could be improved by a systematical division of mobile learning into its respective components. Thus, each component can be checked separately with regard to whether it can cause a culture conflict. Furthermore, there are limitations connected to the conducted focus group workshops (Smithson 2000). According to Smithson (2000) opinions mentioned in the focus group workshops do not belong to the whole group, these are rather discourses that emerged in the context. Even though we utilized several methods, including a moderated discussion and a relevance ranking, it is still possible that some participants dominated the research process.

\section{Conclusion}

With this research paper, we provided a theory-driven design and evaluation of a mobile learning application to overcome culture conflicts in a foreign context. In particular, we drew on the theory of ITculture conflict to identify potential system and vision conflicts in a mobile learning application that is transferred to a Chinese vocational school context. First, we derived requirements from theory to address identified culture conflicts. Second, we derived additional requirements by conducting two focus group workshops to gain a better fit to our target group's values and to overcome the limitations that arise when considering the values of the target group in China as monolithic. In a next step, we addressed all requirements by design elements and implemented them in our mobile learning application. To evaluate how the culturally derived design elements influence learning outcomes, we drew on a quasi-experimental approach and measured affective, cognitive, and skill-based learning outcomes as dependent variables. Our results show a significant improvement of skill-based learning outcomes as well as the acquisition of procedural knowledge. We contribute to theory by appreciating the role of culture in mobile learning and therefore provide guidance how to solve IT-culture conflicts in the design process of TML-related IT artifacts (Gregor 2006). As a practical contribution, we enable mobile learning providers to adapt mobile learning applications to foreign cultural contexts, thus ensuring their successful implementation.

\section{Acknowledgements}

Our thanks go to all participating students of the Yizheng Technician College and the Hefei Vocational and Technical College, as well as Maike Holzmüller and Marian Thiel de Gafenco without whose support the study would not have been possible. The research presented in this paper was partially funded by the German Federal Ministry of Education and Research in the course of the project kuLtig (www.projektkuLtig.de), Grant No. 01BEXo5A13 and the project ExTEND (www.projekt-ExTEND.de), Grant No. 01FJ15127.

\section{References}

Adkins, S. S. 2015. “Ambient Insight's The 2014-2019 Worldwide Mobile Learning Market,"

Alavi, M., and Leidner, D. E. 2001. "Research Commentary: Technology-Mediated Learning - A Call for Greater Depth and Breadth of Research," Information Systems Research (12:1), pp. 1-10.

Anakwe, U. P., Kessler, E. H., and Christensen, E. W. 1999. "Distance Learning and Cultural Diversity: Potential Users' Perspective," International Journal of Organizational Analysis (7:3), pp. 224-243.

Arpaci, I., Yardimci, Y. C., and Turetken, O. 2013. "The impact of cultural differences on smartphone adoption by organizations," in 2013 Third International Conference on Innovative Computing Technology (INTECH), London, United Kingdom, pp. 421-423.

Barbour, R. 2008. Doing Focus Groups, London: Sage publications.

Berry, D. C., and Dienes, Z. (eds.) 1994. Implicit Learning: Theoretical and Empirical Issues: Essays in Cognitive Psychology, Hove (UK): Psychology Press Ltd.

Bhattacherjee, A. 2012. Social science research: Principles, methods, and practices, Tampa, Florida: Anol Bhattacherjee.

Blanchard, E., and Frasson, C. 2005. "Making Intelligent Tutoring Systems culturally aware: The use of Hofstede's cultural dimensions," International Conference in Artificial Intelligence.

Bloom, B. S. 1956. Taxonomy of educational objectives: David McKay New York.

Briggs, R. O. 2006. "On theory-driven design and deployment of collaboration systems," International Journal of Human-Computer Studies (64:7), pp. 573-582. 
Briggs, R. O., Reinig, B. A., and Vreede, G. J. de 2014. "An Empirical Field Study of the Yield Shift Theory of Satisfaction," System Sciences, Proceedings of the 47th Hawaii International Conference on System Science, pp. 492-499.

Chau, P. Y. K., Cole, M., Massey, A. P., Montoya-Weiss, M., and O'Keefe, R. M. 2002. "Cultural differences in the online behavior of consumers," Communications of the ACM (45:10), pp. 138-143.

Chen, A.-Y., Mashhadi, A., Ang, D., and Harkrider, N. 1999. "Cultural Issues in the Design of TechnologyEnhanced Learning Systems," British Journal of Educational Technology (30:3), pp. 217-230.

Chen, Y., and Zahedi, F. M. 2016. "Individuals' internet security perceptions and behaviors: polycontextual contrasts between the United States and China," MIS Quarterly (40:1), pp. 205-222.

Cheung, G. W., and Chow, I. H.-S. 1999. "Subcultures in Greater China: A Comparison of Managerial Values in the People's Republic of China, Hong Kong, and Taiwan," Asia Pacific Journal of Management (16:3), pp. 369-387.

CNNIC 2012. "Reasons for going online via cell phone in China 2012," Mobile internet in China - Statista Dossier 2013, p. 33.

Cyr, D. 2008. "Modeling Web Site Design Across Cultures: Relationships to Trust, Satisfaction, and ELoyalty," Journal of Management Information Systems (24:4), pp. 47-72.

Dienes, Z., and Berry, D. C. 1994. "Theoretical Implications," in Implicit Learning: Theoretical and Empirical Issues: Essays in Cognitive Psychology, D. C. Berry, and Z. Dienes (eds.), Hove (UK): Psychology Press Ltd, pp. 145-168.

Domínguez, A., Saenz-de-Navarrete, J., de-Marcos, L., Fernández-Sanz, L., Pagés, C., and MartínezHerráiz, J.-J. 2013. "Gamifying learning experiences: Practical implications and outcomes," Computers \& Education (63), pp. 380-392.

Downey, S., Wentling, R. M., Wentling, T., and Wadsworth, A. 2005. "The Relationship between National Culture and the Usability of an E-learning System," Human Resource Development International (8:1), pp. 47-64.

Ernst, S.-J., Janson, A., Söllner, M., and Leimeister, J. M. 2015. "When in Rome, do as the Romans do Overcoming Culture Conflicts in Mobile Learning," ICIS 2015 Proceedings.

Fischer, B., and Kopp, B. 2007. "Evaluation of a Western training concept for further education in China," Interculture Journal (6:4), pp. 57-76.

Fraunhofer MOEZ 2012. Treibende und hemmende Faktoren im Berufsbildungsexport aus Sicht deutscher Anbieter. http://berufsbildungsexport-meta.de/system/publications/documents/ooo/ 000/001/original/FraunhoferMOEZ_Studie_Treiber_Hemmnisse_final.pdf?1371046861.

Gallivan, M., and Srite, M. 2005. "Information technology and culture: Identifying fragmentary and holistic perspectives of culture," Information and Organization (15:4), pp. 295-338.

Gao, L. 1998. "Cultural context of school science teaching and learning in the People's Republic of China," Science Education (82:1), pp. 1-13.

Gehlert, A., Schermann, M., Pohl, K., and Krcmar, H. 2009. "Towards a Research Method for Theorydriven Design Research,” Wirtschaftinformatik Proceedings 2009.

Gómez, S., Zervas, P., Sampson, D. G., and Fabregat, R. 2014. "Context-aware adaptive and personalized mobile learning delivery supported by UoLmP," Journal of King Saud University - Computer and Information Sciences (26:1), pp. 47-61.

Green, S. G., and Taber, T. D. 1980. "The effects of three social decision schemes on decision group process," Organizational Behavior and Human Performance (25:1), pp. 97-106.

Greenbaum, T. L. 1998. The handbook for focus group research, Thousand Oaks (CA), London, New Delhi: SAGE.

Gregor, S. 2006. "The nature of theory in information systems," (30:3), pp. 611-642.

Gregor, S., and Hevner, A. R. 2013. "Positioning and Presenting Design Science Research for Maximum Impact," MIS Quarterly (37:2), pp. 337-A6.

Gregor, S., and Jones, D. 2007. "The Anatomy of a Design Theory," Journal of the Association for Information Systems (8:5), pp. 312-335.

Gupta, S., and Bostrom, R. 2013. "An Investigation of the Appropriation of Technology-Mediated Training Methods Incorporating Enactive and Collaborative Learning," Information Systems Research (24:2), pp. 454-469.

Gupta, S., Bostrom, R. P., and Anson, R. 2010. "Do I matter? The impact of individual differences on training process," Proceedings of the 2010 Special Interest Group on Management Information System's 48th annual conference on Computer personnel research, pp. 112-120. 
Hanus, M. D., and Fox, J. 2015. "Assessing the effects of gamification in the classroom: A longitudinal study on intrinsic motivation, social comparison, satisfaction, effort, and academic performance," Computers \& Education (80), pp. 152-161.

Hofstede, G. 1980. Culture's consequences: International differences in work-related values: Sage Publications, Inc.

Hofstede, G. 1986. "Cultural differences in teaching and learning," International Journal of Intercultural Relations (10:3), pp. 301-320.

Holtbrügge, D., and Mohr, A. T. 2010. "Cultural Determinants of Learning style Preferences," Academy of Management Learning \& Education (9:4), pp. 622-637.

Janson, A., Ernst, S.-J., and Söllner, M. 2016. "How Cultural Values Influence the Appropriation of Technology-Mediated Learning," European Conference on Information Systems (ECIS).

Kamentz, E. 2011. Adaptivität von hypermedialen Lernsystemen: Ein Vorgehensmodell für die Konzeption einer Benutzer- modellierungskomponente unter Berücksichtigung kulturbedingter Benutzereigenschaften.

Kamentz, E., and Womser-Hacker, C. 2003. "Defining Culture-Bound User Characteristics as a StartingPoint for the Design of Adaptive Learning Systems," Journal of Universal Computer Science (9:7), pp. 596-607.

Karahanna, E., Evaristo, J. R., and Srite, M. 2005. "Levels of Culture and Individual Behavior: An Integrative Perspective," Journal of Global Information Management (13:2), pp. 1-20.

Koch, H., Leidner, D. E., and Gonzalez, E. S. 2013. "Digitally enabling social networks: resolving ITculture conflict," Information Systems Journal, pp. 501-523.

Kolfschoten, G. L., and Vreede, G.-J. de 2009. "A Design Approach for Collaboration Processes: A Multimethod Design Science Study in Collaboration Engineering," Journal of Management Information Systems (26:1), pp. 225-256.

Koole, M. L. 2009. "A Model for Framing Mobile Learning," in Mobile learning: Transforming the delivery of education and training, M. Ally (ed.), Edmonton: AU Press, pp. 25-44.

Kraiger, K., Ford, J. K., and Salas, E. 1993. "Application of cognitive, skill-based, and affective theories of learning outcomes to new methods of training evaluation," Journal of applied psychology (78:2), pp. $311-328$.

Kukulska-Hulme, A. 2005. "Introduction," in Mobile learning: A handbook for educators and trainers, A. Kukulska-Hulme, and J. Traxler (eds.), London: Routledge, pp. 1-6.

Kummer, T.-F., Leimeister, J. M., and Bick, M. 2012. "On the Importance of National Culture for the Design of Information Systems," Business \& Information Systems Engineering (4:6), pp. 317-330.

Kummer, T.-F., and Schmiedel, T. 2016. "Reviewing the Role of Culture in Strategic Information Systems Research: A Call for Prescriptive Theorizing on Culture Management," Communications of the Association for Information Systems (38:1).

Lee, I., Kim, J., Choi, B., and Hong, S.-J. 2010. "Measurement development for cultural characteristics of mobile Internet users at the individual level," Computers in Human Behavior (26:6), pp. 1355-1368.

Leidner, D. E., and Kayworth, T. 2006. "Review: A Review of Culture in Information Systems Research: Toward a Theory of Information Technology Culture Conflict," MIS Quarterly (30:2), pp. 357-399.

Li, C. 1996. "Rediscovering urban subcultures: The contrast between Shanghai and Bejing," The China Journal (36), pp. 139-153.

Lin, J., and Chen, Q. 1995. "Academic Pressure and Impact in Students' Development in China," McGill Journal of Education (30:2), pp. 149-168.

Manikutty, S., Anuradha, N. S., and Hansen, K. 2007. "Does culture influence learning styles in higher education?” International Journal of Learning and Change (2:1), p. 70.

Marcus, A., and Gould, E. W. 2000. "Crosscurrents: Cultural dimensions and global Web user-interface design," interactions (7:4), pp. 32-46.

Marcus, A., and Gould, E. W. 2012. "Globalization, Localization, and Cross-Cultural User-Interface Design," in The human-computer interaction handbook: Fundamentals, evolving technologies, and emerging applications, J. A. Jacko (ed.), Boca Raton, FL: CRC Press, pp. 341-366.

Martinsons, M., and Ma, D. 2009. "Sub-Cultural Differences in Information Ethics across China: Focus On Chinese Management Generation Gaps," Journal of the Association for Information Systems (10:11), pp. 816-834.

MMB Institute 2015. "MMB-Branchenmonitor 2015: Wachsender E-Learning-Markt attraktiv für Startup-Unternehmen," 
Mushtaha, A., and Troyer, O. 2007. "Cross-Cultural Understanding of Content and Interface in the Context of E-Learning Systems," in Usability and Internationalization. Global and Local User Interfaces, N. Aykin (ed.), Berlin, Heidelberg: Springer Berlin Heidelberg, pp. 164-173.

Nesbit, J. C., and Adesope, O. O. 2006. "Learning With Concept and Knowledge Maps: A Meta-Analysis," Review of Educational Research (76:3), pp. 413-448.

Park, S. 2015. "Virtual Avatar as an Emotional Scaffolding Strategy to Promote Interest in Online Learning Environment," in Emotions, Technology, Design, and Learning, S. Y. Tettegah, and M. Gartmeier (eds.), London, San Diego, Wlatham (MA), Oxford (UK): Academic Press, pp. 201-224.

Peffers, K., Tuunanen, T., Rothenberger, M. A., and Chatterjee, S. 2007. "A design science research methodology for information systems research," Journal of Management Information Systems (24:3), pp. 45-77.

Pieri, M., and Diamantini, D. 2009. "From E-learning to Mobile Learning: New Opportunities," in Mobile learning: Transforming the delivery of education and training, M. Ally (ed.), Edmonton: AU Press, pp. 183-194.

Pierre-Antoine, R., Sheppard, S. D., and Schar, M. 2014. "Utilizing Concept Maps to Improve Engineering Course Curriculum in Teaching Mechanics," Paper presented at 2014 ASEE Annual Conference (June).

Rau, P.-L. P., Gao, Q., and Wu, L.-M. 2008. "Using mobile communication technology in high school education: Motivation, pressure, and learning performance," Computers \& Education (50:1), pp. 122.

Redding, S. G., and Ng, M. 1983. "The role of" face" in the organizational perceptions of Chinese managers," International Studies of management \& Organisation (13:3), pp. 92-123.

Reinecke, K., and Bernstein, A. 2011. "Improving performance, perceived usability, and aesthetics with culturally adaptive user interfaces," ACM Transactions on Computer-Human Interaction (18:2), pp. $1-29$.

Reinecke, K., and Bernstein, A. 2013. "Knowing what a User Likes: A Design Science Approach to Interfaces that Automatically Adapt to Culture," MIS Quarterly (37:2), pp. 427-453.

Renner, D., Laumer, S., and Weitzel, T. 2015. "Blended Learning Success: Cultural and Learning Style Impacts,” Wirtschaftsinformatik Proceedings 2015, pp. 1375-1390.

Schein, E. H. 1984. "Coming to a New Awareness of Organizational Culture," Sloan Management Review (25:2), pp. 3-16.

Seipold, J. 2014. "Mobile learning: Structures, Concepts and Practices of the British and German Mobile Learning Discusssion from a Media Education Perspective,” MedienPädagogik (24), pp. 30-52.

Sha, L., Looi, C., Chen, W., and Zhang, B. H. 2012. "Understanding mobile learning from the perspective of self-regulated learning,” Journal of Computer Assisted Learning (28:4), pp. 366-378.

Smithson, J. 2000. "Using and analysing focus groups: limitations and possibilities," International Journal of Social Research Methodology (3:2), pp. 103-119.

Srite, M., and Karahanna, E. 2006. "The Role of Espoused National Cultural Values in Technology Acceptance," MIS Quarterly (30:3), pp. 679-704.

Straub, D. W. 1994. "The Effect of Culture on IT Diffusion: E-Mail and FAX in Japan and the U.S," Information Systems Research (5:1), pp. 23-47.

Swierczek, F. W., and Bechter, C. 2010. "Cultural Features of e-Learning," in Learning and Instruction in the Digital Age, J. M. Spector, D. Ifenthaler, P. Isaias, Kinshuk, and D. Sampson (eds.), Boston, MA: Springer US, pp. 291-308.

Thiebes, S., Lins, S., and Basten, D. 2014. "Gamifying Information Systems - a Synthesis of Gamification Mechanics and Dynamics," Proceedings of the European Conference on Information Systems.

Traxler, J. 2009a. "Current State of Mobile Learning," in Mobile learning: Transforming the delivery of education and training, M. Ally (ed.), Edmonton: AU Press, pp. 9-24.

Traxler, J. 2009b. "Learning in a Mobile Age," International Journal of Mobile and Blended Learning (1:1), pp. 1-12.

Walker, K. 2006. "Introduction: Mapping the Landscape of Mobile Learning," in Big Issues in Mobile Learning, M. Sharples (ed.), pp. 3-4.

Walls, J. G., Widmeyer, G. R., and El Sawy, O. A. 1992. "Building an Information System Design Theory for Vigilant EIS," Information Systems Research (3:1), pp. 36-59.

Yu, H. 1959. "Shi shuo (on teachers)," in Gu wen guam zhi (A primer of classical Chinese texts), C. Wu, and D. Wu (eds.), Bejing: Zhonghua shuju, pp. 333-335. 